\title{
Greenland under changing climates: sensitivity experiments with a new three-dimensional ice-sheet model
}

\author{
Adeline Fabre, Anne letréguilly, Catherine Ritz and Anne Mangeney \\ Laboratoire de Glaciologie et de Géophysique de l'Environnement, 38402 Saint-Martin-d'Hères Cedex, France
}

\begin{abstract}
A new three-dimensional, time-dependent ice-sheet model, including the calculation of the coupled temperature and velocity fields, isostatic adjustment of the bedrock and a mass-balance parameterization, was used to reconstruct the evolution of the Greenland ice sheet in response to a climate history derived from the oxygen-18 measured in the GRIP ice core. Steady-state experiments were done to test the sensitivity of the model, first to variations of poorly known parameters, secondly to different climates. These experiments show that the modelled ice sheet is not very sensitive to variations in the geothermal heat flux, but very sensitive to changes in the accumulation.
\end{abstract}

\section{INTRODUCTION}

Glaciers and ice sheets respond sensitively to climate change, but their response is difficult to interpret. In this study, we try to improve our understanding of glacierclimate interactions by means of a three-dimensional numerical model of the Greenland ice sheet. Such models were previously developed by Mahaffy (1976), Jenssen (1977), Verbitskii (1981), Reeh (1982), Oerlemans and Van der Veen(1984), Grigoryan (1985), Hall (1987), Huybrechts and Oerlemans (1988), Fastook and Chapman (1989), Lindstrom and MacAyeal (1989) and Calov (1994). The Jenssen, Huybrechts, Lindstrom and Calov models take the coupling of the temperature and velocity fields into account, by solving the model equations on a three-dimensional network. The model we present here belongs to that group.

\section{THE ICE-SHEET MODEL}

The model we developed is a three-dimensional ice-sheet model, including the coupling between the ice temperature and the velocity. The evolution of the ice-sheet geometry results from a mass-balance and a bedrock-adjustment model. The basic equations governing the model are similar to those of other three-dimensional models such as that of Huybrechts (1990). In the shallow-ice approximation, ice deformation results from shear strain only. We will present only the differences with those models.

Horizontal velocity is expressed as:

$$
\begin{array}{r}
u_{x}(z)=-(\rho g)^{3}\left[\left(\frac{\partial S}{\partial x}\right)^{2}+\left(\frac{\partial S}{\partial y}\right)^{2}\right] \frac{\partial S}{\partial x} S_{\mathrm{a}}(z) \\
u_{y}(z)=-(\rho g)^{3}\left[\left(\frac{\partial S}{\partial x}\right)^{2}+\left(\frac{\partial S}{\partial y}\right)^{2}\right] \frac{\partial S}{\partial y} S_{\mathrm{a}}(z)
\end{array}
$$

with

$$
S_{a}(z)=\int_{B}^{z} B_{\mathrm{AT}}(z)(S-z)^{3} \mathrm{~d} z
$$

where $S$ is the ice-sheet surface altitude, $\rho$ the ice density, $g$ the acceleration from gravity, $x$ and $y$ the horizontal coordinates, $z$ the vertical coordinate, positive upwards with the origin at sea level. $B_{\mathrm{AT}}(z)$ is a temperaturedependent parameter appearing in the relation between deformation rate and stress. A tuning coefficient $s f$ is included in $B_{\mathrm{AT}}(z)$.

The equation describing the time evolution of the ice thickness is a diffusion equation with a highly non-linear diffusivity coefficient :

$$
\begin{aligned}
\frac{\partial H}{\partial t} & =-\frac{\partial}{\partial x}\left(D \frac{\partial S}{\partial x}\right)-\frac{\partial}{\partial y}\left(D \frac{\partial S}{\partial y}\right)+M-F \\
D & =-(\rho g)^{3}\left[\left(\frac{\partial S}{\partial x}\right)^{2}+\left(\frac{\partial S}{\partial y}\right)^{2}\right] \int_{B}^{S} S_{\mathrm{a}}(z) \mathrm{d} z
\end{aligned}
$$

where $H$ is the ice thickness, $M$ the mass balance and $F$ the bottom melting. The ice-sheet extent and thickness are generated by the model.

The novelty of the model is that $S_{\mathrm{a}}$ and $\int S_{\mathrm{a}} \mathrm{d} z$ are 
calculated only once and the calculation is optimized (see below). The vertical velocity, which is derived from the incompressibility condition, has also been expressed as a function of $\int S_{\mathrm{a}} \mathrm{d} z$.

The temperature field must be known in order to calculate $S_{\mathrm{a}}$ and $\int S_{\mathrm{a}} \mathrm{d} z$. It is derived from the heat equation, with the following conditions at the boundaries: at the ice-sheet surface, the temperature depends on climate and surface elevation (see next section), while at the ice/bedrock interface, the temperature depends on the geothermal heat flux and the type of base (lower than or at the melting point).

The bedrock adjustment is described by means of a diffusion equation similar to that used by Letréguilly and others (1991b).

\section{SURFACE TEMPERATURE}

The surface temperature is used for the mass balance as well as the upper-boundary condition for the ice temperature. It has three components:

$$
T_{\mathrm{a}}=T_{\mathrm{a} 0}+0.0065\left(S_{0}-S\right)+\Delta T_{\mathrm{clim}} .
$$

$T_{\mathrm{a} 0}$ is the present atmospheric mean annual temperature distribution at the ice-sheet surface, parameterized from a map published by Ohmura (1987). The second component takes into account the changes due to altitude variations of the ice-sheet surface, using a lapse rate. The third component is the time evolution depending on the climate. For this, we use a temperature record derived from the $\delta^{18} \mathrm{O}$ measurements of the GRIP ice core (Dansgaard and others, 1993) as climate forcing during 250000 years. The record spans the last glacial interglacial cycle entirely, and most of the one before that. Doubts exist as to the validity of the record prior to 85000 BP (Grootes and others, 1993). However, even if the details of the record are uncertain prior to $85000 \mathrm{BP}$, it is useful for the experiment to simulate the ice-sheet evolution during two full climate cycles. For our model study, we filtered some of the high-frequency variations with a spline smoothing. The original record and the smoothed one are shown in Figure 4a.

\section{MASS BALANCE}

The mass-balance distribution is composed of accumulation, ablation, calving and bottom melting. Since each of these respond differently to changes in temperature, they are parameterized separately.

\section{Accumulation}

We used the present accumulation distribution Ohmura and Reeh, 1991), corrected for climatic temperature variations and changes in the ice-sheet surface slope according to the equation:

$$
\begin{aligned}
\operatorname{acc}(t)=\operatorname{acc}(0) & \times \exp \left(0.078 \times\left(T_{\mathrm{a}}-T_{\mathrm{a} 0}\right)\right) \\
& \times \min \left(1.5, \frac{\alpha+0.001}{\alpha_{0}+0.001}\right)
\end{aligned}
$$

where $\operatorname{acc}(t)$ and $\operatorname{acc}(0)$ are accumulation rates at time $t$ and the present time, respectively, and $\alpha$ and $\alpha_{0}$ are the surface slopes of the ice sheet at time $t$ and at the present time, respectively. The exponential factor in this equation comes from a study of past accumulation rates of the GRIP ice core, central Greenland (Dahl-Jensen and others, 1993). The second factor has been introduced to take into account the changes in the orographic component of the precipitation when the ice sheet is very different from the present one. Because the Greenland bedrock topography is in some places mountainous and very irregular, the 0.001 and 1.5 coefficients ensure that the factor varies between reasonable limits. During glacial conditions, for an ice sheet only slightly larger than the present one, the orographic correction term does not deviate much from 1. It becomes more important for climate warming when a large part or all of the ice sheet may disappear. The orographic correction then shifts the areas of high accumulation towards more sloping grounds.

For a climatic temperature decrease of $10^{\circ} \mathrm{C}$, representing the Last Glacial Maximum, and no change in the icesheet surface, accumulation rates calculated from Equation (6) are $46 \%$ of the present value. For a climatic increase of $5^{\circ} \mathrm{C}$, corresponding to the maximum of the previous Interglacial, accumulation rates are $148 \%$ of the present value, all other things kept constant. The amplitude of accumulation changes as a function of temperature changes is higher than that used with the Huybrechts model for the Greenland experiments Huybrechts and others, 1991; Letréguilly and others, 1991a, b).

\section{Ablation}

Ablation is described by means of Reeh's (1991) positive degree-day model. In the model, air temperature and snow accumulation determine the melt processes. However, the model allows for the possibility of having positive temperatures (and melt) even when the average daily temperature indicates temperatures below the freezing point. Different melt rates are used to melt snow and ice, in order to account for the albedo difference (Braithwaite and Olesen, 1989). The production of superimposed ice is taken into account in the accumulation/ablation process, and the warming that is created by phase changing at the snow or ice surface is included in the surface temperature of the ice sheet.

\section{Calving and bottom melting}

In Greenland, there are at present no ice shelves large enough to have a significant role in the ice-sheet dynamics. Even with the lower sea-level stand of the glacial climate, they are unlikely to have extended much beyond the coastline. Accordingly, ice shelves are not included in the model. The ice lost by calving is usually estimated to be of the same order of magnitude as ablation. In the model, calving is simulated by setting the ice thickness to zero when ice reaches the coastline. The coastline was kept fixed at the present position, corresponding to a zero sea level. The error resulting from this assumption is not very important, as the sea floor around Greenland is steep.

The amount of ice lost by bottom melting is negligible compared to the global mass balance of the ice sheet. 


\section{NUMERICAL METHOD AND SPEGIAL FEATURES OF THE MODEL}

Ice temperature and velocity must be calculated through the depth of the ice, which means solving the model equations on a three-dimensional network of grid points. We did so by means of finite differences, on a network of $41 \times 71$ grid points in the horizontal with a spacing of $40 \mathrm{~km}$, and 11 evenly spaced grid points in the vertical. The bedrock and ice-sheet-surface topography are derived from the $20 \mathrm{~km}$ spaced data set that was used for the experiments with the Huybrechts model (Huybrechts and others, 1991; Letréguilly and others, $1991 \mathrm{a}, \mathrm{b})$. In order to avoid boundary problems at the bedrock and the ice-sheet surface with the threedimensional variables, such as temperature and velocity, the vertical coordinate was scaled to the ice thickness. This also has the advantage of making it possible to greatly simplify the writing of the velocity and temperature (paper in preparation by C. Ritz).

Another particular feature of the model concerns the integrals $S_{\mathrm{a}}$ and $\int S_{\mathrm{a}} \mathrm{d} z$ in Equations (1) and (4). Since these are used in the calculation of ice-thickness evolution as well as the velocity field, which in turn is used for the temperature field, special attention was given to its calculation. In a finite-difference model, all variables are assumed to behave linearly between the grid points, so that the temperature can be expressed as a linear function of depth between the grid points. Instead of using an ordinary numerical integration, $B_{\mathrm{AT}}\left(z^{\prime}\right)\left(S-z^{\prime}\right)^{3}$ was expressed, by means of a Taylor's expansion, in such a way that the integral has an analytical solution for the interval between two grid points (paper in preparation by C. Ritz). This method is more exact, and ensures that no deformation is lost in the lowermost layer of grid points because of the discontinuity at the ice/bedrock interface. Heating caused by deformation in the lowermost layer is also not completely taken into account in the basal grid points, and must be calculated separately and added to the basal heat flux. Huybrechts (1990, etc.) solves these problems in a manner different from ours, by using a network with unevenly spaced vertical grid points, concentrating near the base.

The time step for the ice-thickness evolution and bedrock isostasy is 5 years, and for the mass balance, temperature and velocity 50 years. A model run takes about $30 \mathrm{~min}$ of CPU time for a 200000 year experiment on a Cray-C90 computer.

\section{STEADY-STATE EXPERIMENTS}

Steady-state experiments are performed by imposing a set of initial values of the climate and model parameters under study, and letting the model run 50000 years with unchanged parameters. The first experiment was to ensure that the model could reproduce the present ice sheet when the present climatic conditions were prescribed, with the present state as initial ice-sheet configuration. Values of the model parameters are given in Table 1. Because the enhancement factor $(s f)$ and geothermal heat flux $\left(G_{\mathrm{hf}}\right)$ are poorly known, tests were made to evaluate how uncertainties in these parameters affect the ice sheet for the
Table 1. Values of the parameters used in the model

\begin{tabular}{|c|c|}
\hline$\rho=910 \mathrm{~kg} \mathrm{~m}^{3}$ & Density of the ice \\
\hline$g=9.81 \mathrm{~m} \mathrm{~s}^{-2}$ & Gravity \\
\hline$R=8.314 \mathrm{~J} \mathrm{~mol}^{-1} \mathrm{~K}^{-1}$ & Gas constant \\
\hline$B_{\text {АT } 0}=1.66 \times 10^{-16} \mathrm{~Pa}^{-3} \mathrm{a}^{-1}$ & $\begin{array}{l}\text { Flow-law coefficient for } \\
\qquad \mathrm{T}>-6.5^{\circ} \mathrm{C}\end{array}$ \\
\hline$Q=7.820 \times 10^{4} \mathrm{~J} \mathrm{~mol}^{-1}$ & $\begin{array}{l}\text { Activation energy for } \\
\quad \mathrm{T}>6.5^{\circ} \mathrm{C}\end{array}$ \\
\hline$B_{\mathrm{AT} 0}=2.00 \times 10^{-16} \mathrm{~Pa}^{-3} \mathrm{a}^{-1}$ & $\begin{array}{l}\text { Flow-law coefficient for } \\
\text { T }<-6.5^{\circ} \mathrm{C}\end{array}$ \\
\hline$Q=9.545 \times 10^{4} \mathrm{~J} \mathrm{~mol}^{-1}$ & $\begin{array}{l}\text { Activation energy for } \\
\mathrm{T}<-6.5^{\circ} \mathrm{C}\end{array}$ \\
\hline$s f=3$ & Enhancing flow factor \\
\hline$T_{0}=273.15 \mathrm{~K}$ & $\begin{array}{l}\text { Melting point of ice at } \\
\text { atmospheric pressure }\end{array}$ \\
\hline \multicolumn{2}{|l|}{$k=3.10 \times 10^{8} \exp (-0.0057 T$} \\
\hline$\left.+T_{0}\right) \mathrm{J} \mathrm{m}^{-1} \mathrm{~K}^{-1} \mathrm{a}^{-1}$ & Thermal conductivity \\
\hline$c=2115.3+7.79 T \mathrm{~J} \mathrm{~m}^{-1} \mathrm{~K}^{-1}$ & Specific heat capacity \\
\hline$G_{\mathrm{lff}}=0.042 \mathrm{~W} \mathrm{~m}^{-2}$ & Geothermal heat flux \\
\hline$D a=4 \times 10^{5} \mathrm{~m}^{2} \mathrm{a}^{-1}$ & $\begin{array}{l}\text { Diffusivity of bedrock } \\
\text { model }\end{array}$ \\
\hline$\rho_{\mathrm{m}}=3300 \mathrm{~kg} \mathrm{~m}^{-3}$ & $\begin{array}{l}\text { Density of the mantle } \\
\text { (bedrock) }\end{array}$ \\
\hline
\end{tabular}

present climatic conditions. Results of these tests are summarised in Table 2. None of the changes influences the extent of the ice sheet; only the shape and ice thickness are affected. The ice sheet is more sensitive to the enhancement factor, $s f$, than to any other parameter. Experiment 0 gives the best match with the present ice-sheet topography (see Fig. 1), and is our steady-state reference for the present climate. In all further experiments, the
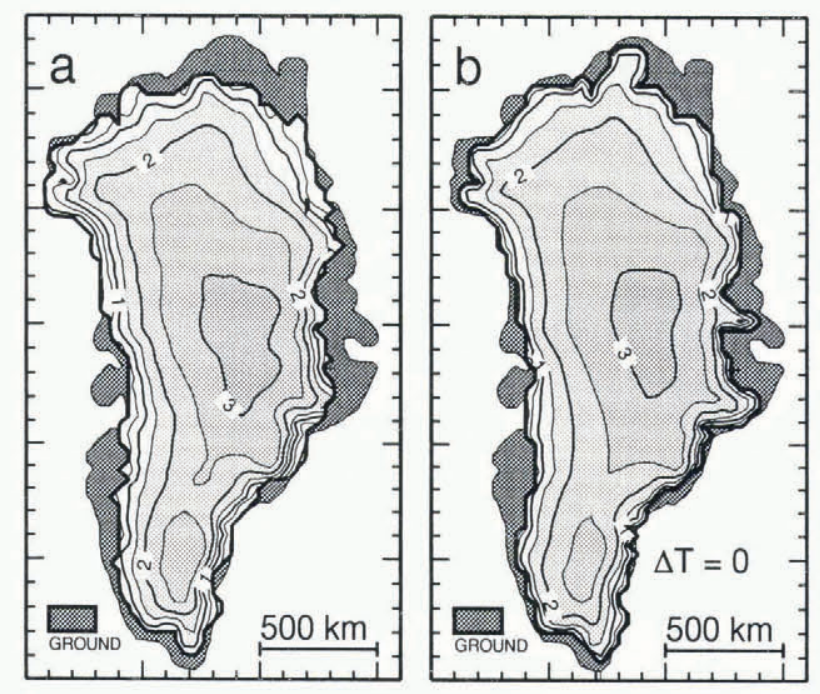

Fig. 1. Maps of the present Greenland ice-sheet thickness digitized on a $40 \mathrm{~km}$ grid. Contour lines (thin lines) represent ice-surface elevation with a contour interval of $0.5 \mathrm{~km}$, starting at $1 \mathrm{~km}$. The thick line indicates the icesheet margin; the dark grey hatching indicates ice-free land above sea level. Left, actual ice sheet; right, steady-state modelled ice sheet. 
Table 2. Summary of the steady-state experiments performed to lest the sensitivity of the least-known parameters of the model, for the present climatic conditions. No. is the experiment number. Model parameters: sf is the softening-enhancement factor of the flow parameter; $G_{\mathrm{hf}}$ is the geothermal heat flux. Model oulpuls: np is the number of grid points covered with ice; $h_{\max }$ and $h_{\text {mean }}$ are the maximum and the average thickness of the ice sheel, respectively; $T_{\mathrm{b}}{ }^{*}$ the mean basal temperature below the pressure melting; Vol the ice sheet volume

\begin{tabular}{|c|c|c|c|c|c|c|c|}
\hline No. & $s f$ & $\begin{array}{c}G_{\mathrm{hf}} \\
\mathrm{W} \mathrm{m}^{-2}\end{array}$ & $n p$ & $\begin{array}{c}h_{\max } \\
\mathrm{m}\end{array}$ & $\begin{array}{c}h_{\text {mean }} \\
\text { m }\end{array}$ & $\begin{array}{c}T_{\mathrm{b}}^{*} \\
{ }^{\circ} \mathrm{C}\end{array}$ & $\begin{array}{l}\text { Vol } \\
\mathrm{m}^{3}\end{array}$ \\
\hline $\begin{array}{l}\text { observed } \\
0 \\
1 \\
2\end{array}$ & $\begin{array}{l}3 \\
1 \\
1\end{array}$ & $\begin{array}{l}0.042 \\
0.042 \\
0.050\end{array}$ & $\begin{array}{l}1105 \\
1114 \\
1109 \\
1111\end{array}$ & $\begin{array}{l}3003 \\
3104 \\
3500 \\
3490\end{array}$ & $\begin{array}{l}1707 \\
1739 \\
2015 \\
2003\end{array}$ & $\begin{array}{l}-3.35 \\
-3.05 \\
-2.38\end{array}$ & $\begin{array}{l}3.02 \times 10^{15} \\
3.10 \times 10^{15} \\
3.58 \times 10^{15} \\
3.56 \times 10^{15}\end{array}$ \\
\hline
\end{tabular}

values $s f=3$ and $G_{\mathrm{hf}}=0.042 \mathrm{~W} \mathrm{~m}^{-2}$ were used (Table 1). About $50 \%$ of the base is at the melting point, in areas away from ice divides.

Experiments were also done for two glacial climates and two warmer climates (Table 3 ). Experiment 0 was used as initial configuration of the ice sheet, and the model was run for 50000 years under the new climatic conditions. For $\Delta T=-10^{\circ} \mathrm{C}$ (Fig. 2a), representing full glacial conditions, the ice sheet reaches the coast nearly everywhere. The ice sheet is thinner than that in experiment 0 , due to the lower accumulation. Correspondingly, the basal temperatures are much colder and are below the melting point almost everywhere. The initial temperature of the series used for the evolution experiment is $\Delta T=-4.5^{\circ} \mathrm{C}$ (Fig. 2b), so a steady-state run was performed for that temperature. The resulting ice sheet is not much different from the full glacial one.

Table 3. Summary of the steady-state experiments performed for different temperature perturbations $\Delta T . s f=3, G_{\mathrm{hf}}=0.042$. No., $n p, h_{\max }, h_{\text {mean }}, T_{\mathrm{b}}{ }^{*}$, Vol are the same as in Table 2

\begin{tabular}{lcccccc}
\hline No. & $\begin{array}{c}\Delta T \\
{ }^{\circ} \mathrm{C}\end{array}$ & $n p$ & $\begin{array}{c}h_{\max } \\
\mathrm{m}\end{array}$ & $\begin{array}{c}h_{\text {mean }} \\
\mathrm{m}\end{array}$ & $\begin{array}{c}T_{\mathrm{b}}{ }^{*} \\
{ }^{\circ} \mathrm{C}\end{array}$ & $\begin{array}{c}\text { Vol } \\
\mathrm{m}^{-3}\end{array}$ \\
\hline 3 & -10 & 1248 & 2997 & 1625 & -8.32 & $3.24 \times 10^{15}$ \\
4 & -4.5 & 1208 & 3031 & 1681 & -5.23 & $3.25 \times 10^{15}$ \\
5 & 5 & 933 & 3154 & 1842 & -2.01 & $2.75 \times 10^{15}$ \\
6 & 7 & 795 & 3122 & 1836 & -1.79 & $2.33 \times 10^{15}$
\end{tabular}

The $\Delta T$ of $5^{\circ} \mathrm{C}$ (Fig. 2c) and $7^{\circ} \mathrm{C}$ (Fig. 2d) represent drastic climate warmings. They were chosen in preference to a more realistic warming because they are necessary for initiating a sizeable retreat of the ice sheet. The icemargin retreat is more pronounced in the north and northeast where the accumulation is the lowest, and in the southwest where the altitude of the bedrock is relatively low. The highest mountain range in Greenland runs along the southern half of the east coast, and another, much lower range along the northern half of the west coast. Because of their higher altitude, these areas (presently under ice) are less sensitive to a warming. The ice sheet appears to be globally more stable than has been found in previous works (Huybrechts and others, 1991; Letréguilly and others, 1991a). This is because of the feedback between mass balance and ice-sheet elevation: for a
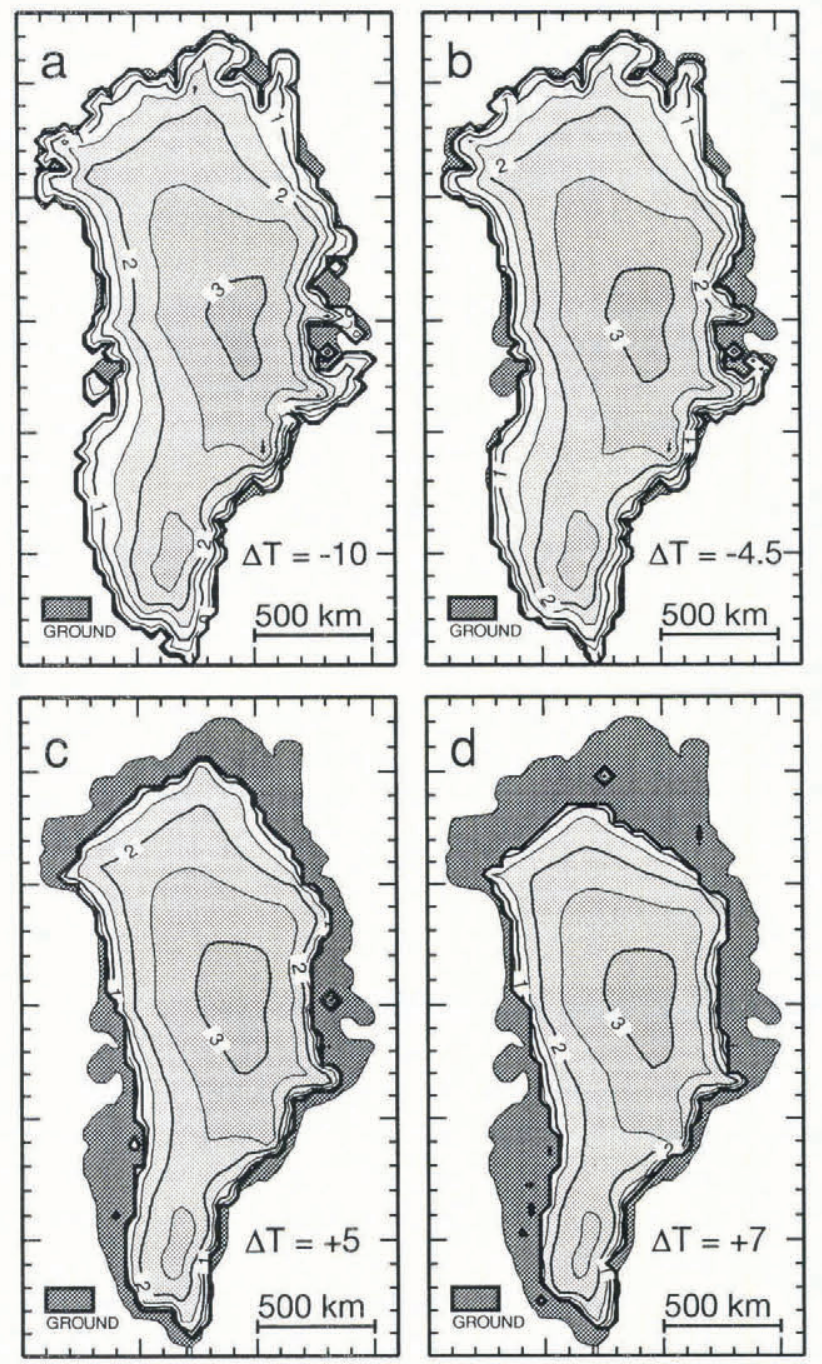

Fig. 2. Sensitivity of Greenland steady-state model to four different climatic parameterizations. Contours represent surface elevation. 
climate warming, the ablation and accumulation both increase. If the ablation increase dominates over the accumulation increase, ice will melt and the surface elevation will decrease. Since temperature at the ice-sheet surface increases for a lowering altitude, the ablation will increase further, creating a strong feed-back. A collapse of the Greenland ice sheet can then be initiated for climates only moderately warmer than the present. The accumulation parameterization used in similar experiments with the Huybrechts model (Letréguilly and others, 1991a) led to such a situation. However, our accumulation parameterization, as given in Equation (6), produces a much higher accumulation increase for warmer climates, and for a temperature change of up to $5^{\circ} \mathrm{C}$ it almost compensates for the ablation increase, so that the ice sheet decreases only slightly.

Two further steady-state experiments were conducted (experiments 7 and 8 ), to show the sensitivity of the ice sheet to the accumulation: Equation (6) was modified so that the accumulation could not increase with the surface temperature. The resulting ice sheets for climate warmings of 3 and $5 \mathrm{C}$ are shown in Figure 3. They are obviously completely different from those in experiments 5 and 6 . For a temperature increase $\Delta T=3 \mathrm{C}$ (experiment 7$)$, the ice sheet breaks into two smaller parts. Because of the increased ablation and margin retreat, the ice advection is no longer large enough to maintain the connection between the two domes of the ice sheet. For a temperature increase $\Delta T=5^{\circ} \mathrm{C}$ (experiment 8 ), the ice sheet disappears almost completely, and only a few isolated ice caps on the highest mountains remain. Table 4 summarises the results obtained for these two experiments.
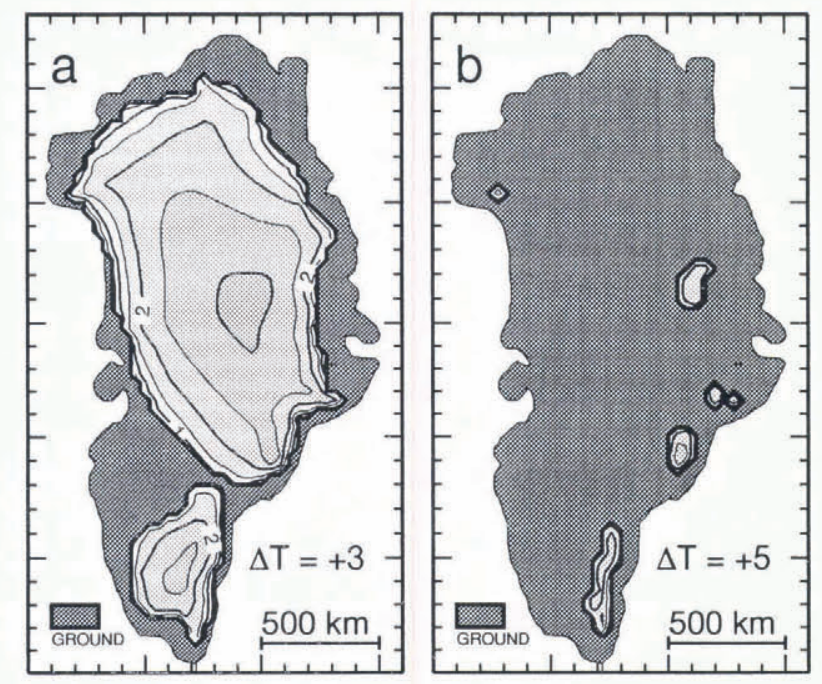

Fig. 3. Maps of the steady-state modelled ice sheet for two warmer climates $\left(\Delta T=3^{\circ} \mathrm{C}\right.$ and $\Delta T=5 \mathrm{C}$ ) with the accumulation limited to the present distribution.

The accumulation parameterization for experiments 7 and 8, although not identical, is close to one used in Letréguilly and others (1991a). A comforting result is that the ice sheet is very close to that obtained with the Huybrechts model, in which the numerical schemes and flow parameters are different. Most models reproduce the
Table 4. Summary of the steady-state experiments performed for different temperature perturbations $\Delta T$, with the modified accumulation. sf $=3, G_{\mathrm{hf}}=0.042$. No., $n p, h_{\text {max }}, h_{\text {mean }}$, $T_{\mathrm{b}}{ }^{*}$, Vol are the same as in Table 2

\begin{tabular}{rrrrrcc}
\hline No. & $\begin{array}{r}\Delta T \\
{ }^{\circ} \mathrm{C}\end{array}$ & $n p$ & $\begin{array}{c}h_{\max } \\
\mathrm{m}\end{array}$ & $\begin{array}{c}h_{\operatorname{mean}} \\
\mathrm{m}\end{array}$ & $\begin{array}{c}T_{\mathrm{b}}{ }^{*} \\
\mathrm{C}\end{array}$ & $\begin{array}{c}\text { Vol } \\
\mathrm{m}^{3}\end{array}$ \\
\hline 7 & 3 & 860 & 3032 & 1750 & -2.34 & $2.41 \times 10^{15}$ \\
8 & 5 & 33 & 054 & 759 & -7.23 & $4.06 \times 10^{13}$ \\
\hline
\end{tabular}

present ice sheet under the present climatic conditions well; however, they usually differ when it comes to simulating the ice sheet under unknown climates.

\section{EVOLUTION EXPERIMENT}

The ice-sheet configuration of experiment 4 was used as initial state, and the time-dependent temperature forcing derived from the GRIP ice core was used as climate input. The results of the evolution experiment are shown in Figure 4. The accumulation parameterization given in Equation (6) was used.

The changes in the ice-sheet volume and area are not very dramatic. Changes in area (Fig. 4e) depend mostly on ablation, while changes in the maximum ice thickness (Fig. 4d) depend mostly on accumulation. The ice volume depends on both accumulation and ablation: large changes such as those of 130000 years and the present result from the margin retreat due to ablation increase, while smaller changes such as those that occurred during the glacial periods result from the icethickness changes. Margin moves are then limited because the ice sheet reaches the coast nearly everywhere. The basal temperature (Fig. 4f) seems to follow the surface temperature forcing, but with a lag of a few thousand years, and much damped: the surface temperature change from the glacial to the Interglacial is $10^{\circ} \mathrm{C}$, while it is only $3 \mathrm{C}$ at the base. The colder basal temperatures of the Glacial Period may be expected to create harder basal ice, leading to a thickening of the ice sheet. In our experiment, what happens may seem at first glance to be the opposite, because the maximum ice thickness depends mostly on the accumulation-rate changes. However, the fact that the general trend of the maximum ice thickness (Fig. 4d) during the last Glacial Period is relatively constant, while the general trend in surface temperature decreases during the same period, can probably be explained by the increasing stiffening of the basal ice.

The resulting ice-sheet topography for the present is $100 \mathrm{~m}$ thicker in the centre than that of experiment 0 , and basal temperatures are $4 \mathrm{C}$ lower. They are still influenced by the Ice Age conditions.

As with the steady-state experiments, the results of the evolution run differ from those of a previous study with the Huybrechts model (Letréguilly and others, 1991b). The temperature time series used as climate forcing differs, but 


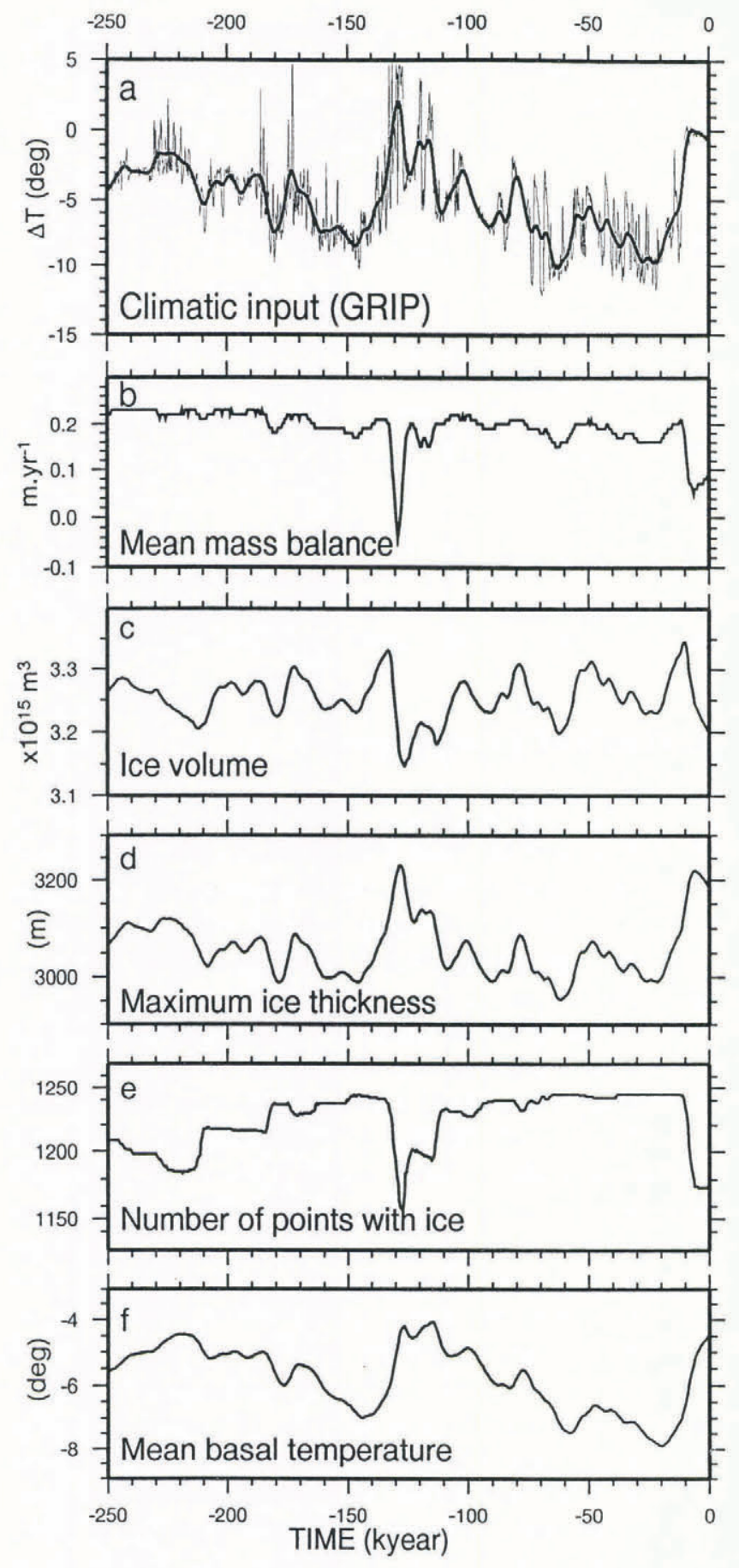

Fig. 4. Ice-sheet-evolution experiment. a. Temperature record derived from the $\delta^{18} \mathrm{O}$ measurements performed on the GRIP deep ice core, at Summit, central Greenland (thin line), with the spline smoothing (thick line) that was used as climatic-variations input for the model. $b, c, d$, $e$ and $f$ show the evolution of selected key variables: $b$. Mass balance; c. Ice volume; d. Maximum ice thickness; e. Number of points with ice; $f$. Basal temperature. $b$ and $f$ are averaged over the number of points of the ice sheel.

the main difference comes from the accumulation parameterization. In the previous study, accumulation was not allowed to rise above the present accumulation rates for warmer climates. The two accumulation parameterizations represent extreme situations, reality probably being somewhere in between. For glacial climates, accumulation rates can be inferred from the ice cores, but for a warmer climate there is no history to guide us as to what the accumulation increase should be. It is then difficult to choose a parameterization. General circulation models may provide an answer when the particularities of the polar climates are better accounted for and their spatial resolution is sufficiently refined.

\section{CONGLUSION}

The ice-sheet model presented in this work is able to reproduce the present topography of the Greenland ice sheet well. Future improvements to the model will include sea-level change and heat conduction in the bedrock. In this study, limited available computing time made it difficult to take heat conduction into account, because the model would have taken much more than 50000 a to approach steady state. Considering the large areas of the base reaching the melting temperature, a sliding law is needed. Since the ice viscosity depends on the age and formation conditions of the ice, we additionally plan to use a flow law taking ice transitions into account. To do that, the ageing of the ice will have to be computed. Finally, we plan to do some experiments with the finer, $20 \mathrm{~km}$ grid, in order to have a more detailed simulation of the ice sheet.

Experiments were conducted to test the model's sensitivity to some poorly known parameters. They show that the modelled ice sheet is only slightly sensitive to a $20 \%$ variation in the geothermal heat flux, but that the ice thickness is very dependent on the tuning flow parameter, $s f$.

The main result of the study concerns the sensitivity of the modelled ice sheet in a warmer climate to the type of accumulation parameterization used: for a temperature increase of $5^{\circ} \mathrm{C}$, one parameterization results in a margin retreat of $0-120 \mathrm{~km}$ (three grid points), the rest of the ice sheet being little changed, while the other results in a complete collapse of the ice sheet. Unfortunately, little evidence is available predicting what the accumulation in warmer climates should be.

\section{ACKNOWLEDGEMENTS}

The ice-sheet model in this work was run on the Cray C90 of the Commission à l'Energie Atomique (CEA) of Grenoble, and on the Cray C90 of the Institut du Développement et des Ressources en Informatique Scientifique (IDRIS) in Orsay. The maps of Greenland were produced using the GMT (Wessel and Smith, 1991) graphics sofware. We thank J. Jouzel and S. Johnsen for providing the data on the GRIP ice-core temperatures.

\section{REFERENCES}

Braithwaite, R.A. and O.B. Olesen, 1989. Calculation of glacies ablation from air temperature, West Greenland. In Oerlemans, J., ed. Glacier fluctuations and climatic change. Dordrecht, Kluwer Academic Publishers, 219233.

Calov, R. 1994. Das thermomechanische Verhalten des grönländischen Eisschildes unter der Wirkung verschiedener KlimaszenarienAntworten eines theoretisch-numerischen Modells. Ph.D. thesis, Technische Hochschule Darmstadt. 
Dahl-Jensen, D., S.J. Johnsen, C. U. Hammer, H. B. Clausen and J. Jouzel. 1993. Past accumulation rates derived from observed annual layers in the GRIP ice core from Summit, central Greenland. In Peltier, W. R., ed. Ice in the climate system. Berlin, etc., Springer-Verlag. $517-531$.

Dansgaard, W. and 10 others. 1993. Evidence for general instability of past climate from a 250-kyr ice-core record. Nature, 3646434$), 218$ 220.

Fastook, J. L. and J. E. Chapman. 1989. A map-plane finite element model : three modeling experiments. J. Glaciol., 35 119), 48-52.

Grigoryan, S.S., S. A. Buyanov, M. S. Krass and P. A. Shumskiy. 1985. The mathematical model of ice sheets and the calculation of the evolution of the Greenland ice sheet. J. Glaciol., 31 (109), 281292.

Grootes, P. M., M. Stuiver, J. W. C. White, S. Johnsen and J. Jouzel. 1993. Comparison of oxygen isotope records from the GISP2 and GRIP Greenland ice cores. Nature, 366 6455), 552-554.

Huybrechts, P. 1990. A 3-D model for the Antarctic ice sheet: a sensitivity study on the glacial interglacial contrast. Climate Dynamics, 52 . 79-92.

Huybrechts, P. and J. Oerlemans. 1988. Evolution of the East Antarctic ice sheet: a numerical study of thermo-mechanical response pattern with changing climate. Ann. Glaciol.. 11, 52-59.

Huybrechts, P., A. Letréguilly and N. Reeh. 1991. The Greenland ice sheet and greenhouse warming. Palaeogeogr., Palaeoclimatol., Palaeoecol., $89(4), 399-412$.

Jenssen, D. 1977. A three-dimensional polar ice-sheet model. J. Glaciol., $1880), 373-389$.

Letréguilly, A., P. Huybrechts and N. Reeh. 1991a. Steady-state characteristics of the Greenland ice sheet under different climates. f. Glaciol., 37 125), 149-157.

Letréguilly, A., N. Reeh and P. Huybrechts. 1991b. The Greenland ice sheet through the last glacial-interglacial cycle. Palaeogeogr., Palacoclimatol., Palacoecol., 90 4, 385-394.

Lindstrom, D. R. and D. R. MacAyeal. 1989. Scandinavian, Siberian. and Arctic Ocean glaciation: effect of Holocene atmospheric $\mathrm{CO}_{2}$ variations. Science, $\mathbf{2 4 5} 4918$ ), 628631.

Mahaffy, M. W. 1976. A three-dimensional numerical model of ice sheets: tests on the Barnes Ice Cap, Northwest Territories. J. Geophys. Res., 81 6), 1059-1066.

Oerlemans, J. and C.J. van der Veen. 1984. Ice sheels and climale. Dordrecht, etc., D. Reidel Publishing Company.

Ohmura, A. 1987. New temperature distribution maps for Greenland. Z. Gletscherkd. Glazialgeol., 23 (1), 1-45.

Ohmura, A. and N. Rech. 1991. New precipitation and accumulation maps for Greenland. J. Glaciol., 37 125), 140-148.

Reeh, N. 1982. A plasticity theory approach to the steady-state shape of a three-dimensional ice sheet. J. Glaciol., 28 100, 431-45.

Reeh, N. 1991. Parameterization of melt rate and surface temperature on the Greenland ice sheet. Polarforschung, 59 3), 1989, 113-128.

Verbitskiy, M.Ya. 1981. Chislennye eksperimenty po gidrotermodinamike lednikovykh shchitov Vostochnoy Antarktidy i Grenlandii [Numerical experiments on the hydrodynamics of the East Antarctic and Greenland ice sheets]. Mater. Gilyatsiol, Issled. Khron. Obsuzhdeniva $40,51-58$.

Wessel, P. and W.H.F. Smith. 1991. Free software helps map and display data. EOS, 72 41), 441, 445446. 